筑 波 大 学

博士（医学）学位論文 


\section{The neuroprotective effect of perampanel in lithium-pilocarpine rat seizure model}

$$
\begin{gathered}
\text { (ペランパネルのリチウムピロカルピンラット } \\
\text { モデルにおける神経保護作用 })
\end{gathered}
$$

\section{7}

筑波大学大学院博士課程人間総合科学研究科

$$
\text { 咫 婷 }
$$




\section{CONTENTS}

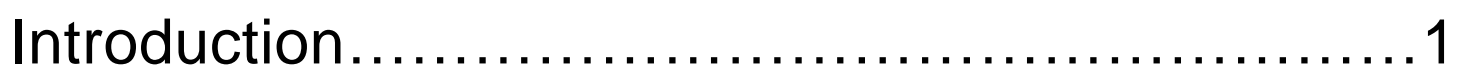

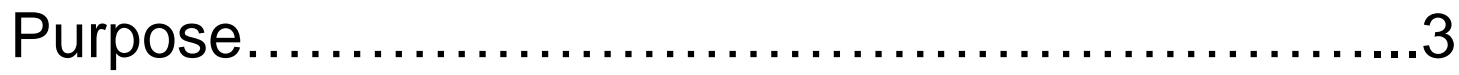

Materials and Methods................................. 4

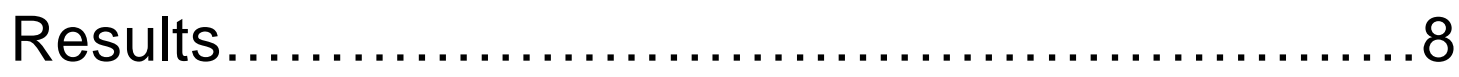

Discussion.......................................

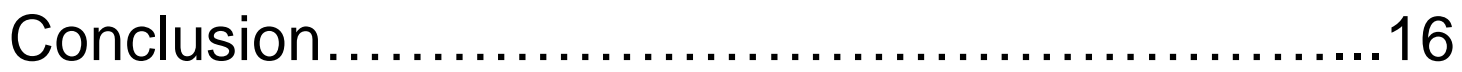

References.......................................... 17

Figures..................................... 27

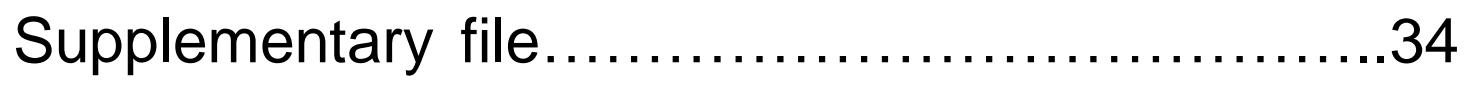




\section{Introduction}

Status epilepticus (SE) carries a risk of major morbidity or mortality (Lowenstein and Alldredge, 1998; Rossetti and Lowenstein, 2011). There are many treatments for SE, including benzodiazepines such as diazepam (DZP) and lorazepam (Meierkord et al., 2006, 2010; Brophy et al., 2012). However, 30$43 \%$ of SE cases become refractory to drugs (Holtkamp et al., 2005; Mayer et al., 2002). Prolonged seizure results in neuronal injury, neuronal death, and alteration of neuronal networks that can result in death or spontaneous recurrent seizures (SRS) and cognitive impairment that will impact the patient's whole life (Curia et al, 2014; Trinka et al., 2015). Many approved antiepileptic drugs (AEDs) have been examined in various animal models of SE, some of them showed that DZP can terminate seizure (Eslami et al., 2016; Imran et al., 2015; Suchomelova et al., 2006). However, there still few AEDs that produce complete and immediate termination of prolonged seizures (Rossetti and Lowenstein, 2011; Löscher and Brandt, 2010). This suggests a need for AEDs with novel mechanisms to treat drug-resistant SE.

Alpha-amino-3-hydroxy-5-methylisoxazole-4-propionic acid (AMPA) receptor antagonists act as broad-spectrum anticonvulsants in animal seizure models (Rogawski and Donevan, 1999). Continuous infusion of NS1209 and repeated injection of GYKI52466 each terminated prolonged seizures in animal models of SE (Pitkänen et al., 2007; Fritsch et al., 2010). However, neither drug alone was able to stop seizures with a single dose. Perampanel (PER), a noncompetitive 
AMPA receptor antagonist, is currently approved for the adjunctive treatment of partial-onset seizures, with or without secondary generalized seizures, and for primary generalized tonic-clonic seizure in patients 12 years and older. In a previous report, a single PER treatment terminated DZP-resistant SE on electroencephalography (EEG) when given 30 minutes after SE initiation (Hanada et al., 2014). This result suggests that PER has a higher potential for suppressing refractory SE than other AEDs and other investigational AMPA antagonists.

Neuronal damage is as important as seizure duration when considering the prognosis of refractory SE, but AEDs used in clinical practice have shown limited effects on reducing neuronal damage in preclinical models (Löscher and Brandt, 2010). NS1209 exerted only mild neuroprotective effects, and no pathological analysis has been performed for GYKI52466 (Pitkänen et al., 2007; Fritsch et al., 2010). The efficacy of PER has only been demonstrated with EEG changes (Hanada et al., 2014), and its impact on neuronal injury has not been explored. The lithium-pilocarpine rat model is known to reproduce clinical and neuropathological features of human SE (Dubé et al., 2006; Clifford et al., 1987; Turski et al., 1989; Curia et al., 2014). In this model, administration of lithium and pilocarpine causes SE, which leads to severe neuronal damage mainly in the hippocampus, piriform cortex, entorhinal cortex, amygdala, and thalamus (Clifford et al., 1987). 


\section{Purpose}

In this study, we examined whether PER has neuroprotective effects in brain areas that can be severely damaged by SE: the CA1 subregion of the hippocampus, the piriform cortex (Pir), and the mediodorsal thalamus (MD). We also examined the relationship between neuroprotection and seizure suppression. 


\section{Materials and Methods}

\section{Animals}

Male Sprague Dawley rats (6 weeks old) were purchased from Charles River Laboratories Japan, Inc. (Kanagawa, Japan). The rats were housed with artificial lighting of 12 hours light (7 a.m. to 7 p.m.), 12 hours dark. Rats were provided with pellet food (MF, Oriental Yeast Co., Japan) and tap water ad libitum. All procedures were performed in the animal facility accredited by the Center for Accreditation of Laboratory Animal Care and use Japan Health Sciences Foundation. All protocols were approved by the Institutional Animal Care and Use Committee and carried out according to the Eisai Animal Experimentation Regulations.

\section{Induction of SE and treatment protocol}

SE was induced by the administration of lithium chloride (Wako Pure Chemical Industries, Japan) (3 mEq/kg, i.p.), followed 18-24 hours later by scopolamine methyl bromide (Sigma-Aldrich, Japan) (5 mg/kg, i.p.) and pilocarpine (Wako Pure Chemical Industries, Japan) (30 mg/kg, i.p.) (Curia et al., 2008). The test drugs, PER (Eisai Co., Ltd, Kashima, Japan) and DZP (Wako Pure Chemical Industries, Japan), were diluted with a vehicle consisting of distilled water, dimethyl sulfoxide, and polyethylene glycol 300, at 1:1:1 (v/v). In accordance with a previous study (Hanada et al., 2014), three doses of PER were used: 0.6 
$\mathrm{mg} / \mathrm{kg}(\mathrm{n}=15), 2 \mathrm{mg} / \mathrm{kg}(\mathrm{n}=15)$, or $6 \mathrm{mg} / \mathrm{kg}(\mathrm{n}=8)$. In the present study, DZP rather than vehicle was used as the control to reduce mortality. PER or DZP 10 $\mathrm{mg} / \mathrm{kg}(\mathrm{n}=6)$ were administered (i.v.) 30 min after the initiation of SE, which was defined as continuous seizures with rearing accompanied by bilateral forelimb clonus (Racine score 4; Racine, 1972). The latency to SE initiation was evaluated in all rats and analyzed by group, in accordance with a previous study (Lucchi et al., 2013). A treatment-naive group $(n=9)$ of rats not administered lithium chloride and pilocarpine to induce seizure was also included.

\section{Behavioral observation}

Seizure was classified in accordance with the Racine score (Racine, 1972) as follows: score 0 - no seizure behavior; score 1 - immobility, eye closure, twitching of vibrissae, sniffing, facial clonus; score 2 - head nodding associated with more severe facial clonus; score 3 - clonus of one forelimb; score 4 rearing, often accompanied by bilateral forelimb clonus; score 5 - score 4 with loss of balance and falling, accompanied by generalized clonic seizures. The efficacy of drugs on seizure suppression was evaluated by using the Racine score 30 min after drug administration.

\section{Immunohistochemical procedure}

Animals were deeply anesthetized one week after SE induction and perfused 
with saline, followed by $4 \%$ paraformaldehyde in $0.1 \mathrm{M}$ phosphate-buffered saline (PBS) $(\mathrm{pH} 7.0)$. The brains were removed, post-fixed with $4 \%$ paraformaldehyde in PBS, and cryoprotected with $30 \%$ sucrose in PBS. Frozen sections were cut at $30 \mu \mathrm{m}$ and stored in $0.05 \% \mathrm{NaN}_{3}$ in PBS. Slices taken from $-3.8 \mathrm{~mm}$ relative to bregma were used for immunostaining. These selected floating sections were stained with anti-neuronal nuclei (NeuN) antibody (1:500, Chemicon International, Inc., USA), which was used to determine neuronal loss in CA1, Pir, and MD. Secondary antibody was Biotinylated horse anti-mouse IgG (1:200, Vector Laboratories, USA). It was followed by the addition of avidinbiotin-peroxidase complex (VECTASTAIN Elite ABC HRP Kit, Vector Laboratories, USA). The peroxidase was then developed by the diaminobenzidine (DAB reagent, Vector Laboratories, USA).

\section{Quantification of NeuN expression}

Slides in each group were scanned (Aperio Technologies, USA), and the NeuNpositive cells were detected with a positive pixel-count algorithm (ImageScope, Aperio Technologies, Inc., USA) that quantifies the amount of a specific stain (Liu et al., 2008). In this algorithm, the brown color of DAB on images of the tissues was identified as being weakly positive, positive, or strongly positive. For pixels that meet the color specification, the algorithm counted the number in each intensity range. In the present study, the whole CA1, Pir, and MD regions were analyzed, and the pixels with positive or strongly positive intensity were 
counted. The average pixel counts of each group across all sections were calculated. All of these analyses were performed by an investigator blinded to the treatment groups. Samples were photographed with a fluorescence microscope (BZ-X700 / BZ-710, KEYENCE, Japan) for expressing the images of each treatment group.

\section{Statistical analysis}

The survival rate was analyzed with Fisher's exact test. The latency to SE initiation was analyzed with one-way analysis of variance (ANOVA), followed by Dunnett's multiple comparison tests. Seizure score was analyzed with one-way ANOVA with Dunn's multiple comparison tests. The percentage of pixel counts was compared between the naive and DZP group with Student's $t$ test, and between the DZP group and the groups given different doses of PER with oneway ANOVA with Dunnett's multiple comparison tests. The correlation of SE seizure suppression effects and neuroprotective effects was analyzed with Pearson's correlation coefficient analysis. GraphPad Prism software (Version. 6.07, GraphPad Software, Inc., USA) was used for all statistical analysis. The graphs of correlation were drawn with JMP software (Version. 12.2.0, SAS Institute Inc., USA). The level of significance was set to $p<0.05$. 


\section{Results}

\section{Survival rate}

All animals given $10 \mathrm{mg} / \mathrm{kg}$ DZP survived. PER dose-dependently increased the survival rate from $40 \%$ in animals given $0.6 \mathrm{mg} / \mathrm{kg}$ which was significantly lower than in the naïve group, to $100 \%$ in animals given 2 or $6 \mathrm{mg} / \mathrm{kg}$ PER.

2 Effects of DZP and PER on seizure in lithium-pilocarpine-induced SE

The latencies to SE initiation were not different among the groups administered DZP and PER (Supplementary Table 1). All the animals in the group administered DZP $(n=6)$ showed a Racine score of 5 (Fig. 1). In contrast, administration of $6 \mathrm{mg} / \mathrm{kg}$ PER terminated seizures in all animals $(n=8)$. Seizures were terminated in 7 of $15(47 \%)$ of the animals in the group given 2 $\mathrm{mg} / \mathrm{kg}$ PER. Seizure severity was suppressed to a Racine score $<2$ in $75 \%$ $(6 / 8)$ of the remaining animals in this group. At a dose of $0.6 \mathrm{mg} / \mathrm{kg}$, PER did not suppress seizures, and all 6 animals in this group had Racine scores of 5 , as was seen in the DZP group (Fig. 1).

3 Effects of DZP and PER on neuronal loss in animals following lithiumpilocarpine-induced SE 
The DZP-treated group exhibited more extensive neuronal loss in CA1, Pir, and MD than the naive group (Fig. 2, A-F). Pixel counts of the naive group in each area were set to $100 \%$. The DZP-treated animals exhibited a significant reduction of pixel counts to $22.2 \%, 8.5 \%$, and $23.2 \%$ of the naive values in CA1, Pir, and MD, respectively (Fig. 3, A, C, E). The most severe neuronal loss was observed in the Pir area. In contrast, PER dose-dependently prevented neuronal loss, and at higher doses the pixel counts, representing the level of preserved neurons, were comparable to those in the naive group (Fig. 2, G-R; Fig. 3, A, C, E).

In the group treated with $6 \mathrm{mg} / \mathrm{kg}$ PER, neurons were preserved in CA1, Pir, and MD (Fig. 2, P-R) at 105.3\%, 111.7\%, and 92.4\%, respectively, of the levels in the naive group (Fig. 3, A, C, E). These levels were significantly higher than those in the DZP-treated group.

In rats treated with $2 \mathrm{mg} / \mathrm{kg}$ PER, the pixel counts in CA1, Pir, and MD were $83.9 \%, 90.0 \%$, and $92.4 \%$, respectively, of the counts in naive rats (Fig. 3, A, C, E). The rats in this group were divided into two subgroups for analysis: one in which the seizures were continued and one in which the seizures were terminated. The seizure-free group exhibited nearly the same pixel counts as the naive group: $101.7 \%, 102.7 \%$, and $90.3 \%$ of naive group in CA1, Pir, and $M D$, respectively (Fig. 3, B, D, F). All three of the values were significantly higher than the corresponding values in the DZP-treated group (Fig. 2, M-O; Fig. 3, B, D, F). 
Even in the group with continued seizures, PER provided more neuroprotective effects than DZP (Fig. 2, J-L). The pixel counts in CA1, Pir, and MD were $68.4 \%, 78.8 \%$, and $94.3 \%$ of those in the naive animals, respectively (Fig.3, B, $D, F)$.

In rats treated with $0.6 \mathrm{mg} / \mathrm{kg}$ PER, the pixel counts in CA1, Pir, and MD were $45.2 \%, 40.6 \%$, and $38.0 \%$, respectively, of the counts in naive rats (Fig. 3, A, C, E). These values were not significantly different from those in the DZP-treated group.

To analyze the correlation between seizure suppression and neuroprotective effect, pixel counts were plotted against seizure score (Fig. 4). The neuroprotective effect was significantly inversely correlated with seizure score, with Pearson's $r$ values of -0.72 for CA1, -0.68 for Pir, and -0.52 for MD (Fig. 4 $A-C)$. 


\section{Discussion}

In the present study, PER potently suppressed seizures and prevented neuronal loss in DZP-resistant SE. DZP is used for SE management clinically, but its ability to suppress seizures typically declines when the duration of SE increases. The mechanism of this decline has been reported to be the functional loss of postsynaptic GABAA receptors (Naylor et al., 2005; Goodkin et al., 2005, 2008). In this study, DZP neither terminated seizures nor prevented neuronal degeneration. In the lithium-pilocarpine SE model, seizure is initiated by the activation of the cholinergic system, whereas the continuation of seizure activity is thought to occur via a glutamatergic mechanism (Clifford et al., 1987). It has also been reported that AMPA-mediated neuronal transmission is preserved in the lithium-pilocarpine model (Chen et al., 2007). These reports could explain the potent effect of PER on both seizure and neurodegeneration in DZP-resistant prolonged SE.

A neuroprotective effect of PER was observed in all three of the analyzed brain areas. Neuronal survival was correlated with seizure score at evaluation, which is consistent with a previous report (Gorter et al., 2003) and supports the importance of early seizure termination for preventing neuronal injury. Although we did not monitor the seizure over time until sacrifice in the present study, our preliminary data (not shown) suggested than seizures did not recur in the PER administered group until five hours after treatment. This would also contribute to the neuroprotective effect. Several reports suggest that the neuronal loss in SE 
occurs secondary to seizure and that AMPA receptors are involved in these sequential actions. Continuous seizure results in excessive neuronal excitability due to significant elevations in extracellular glutamate (Wasterlain et al., 1993; Heinemann et al., 2002a, 2002b). The increased glutamate causes excessive stimulation of postsynaptic glutamate receptors and overload of $\mathrm{Ca}^{2+}$, leading to neuronal death (Choi, 1988). The $\mathrm{Ca}^{2+}$ overload occurs in part because AMPA receptors change from $\mathrm{Ca}^{2+}$ impermeable to $\mathrm{Ca}^{2+}$ permeable in the presence of increased glutamate (Rajasekaran et al., 2012; Grooms et al., 2000), and the increased $\mathrm{Ca}^{2+}$ influx through AMPA receptors can cause cell death (PellegriniGiampietro et al., 1997). PER can inhibit both $\mathrm{Ca}^{2+}$-permeable and $\mathrm{Ca}^{2+}$ impermeable AMPA receptors (Barygin, 2016). Efficient inhibition of $\mathrm{Ca}^{2+}$ permeable receptors by PER might prevent neuronal damage in rats with severe seizures.

The potent effects of a single dose of PER on both SE termination and prevention of neuronal loss have not been observed even with other AMPA receptor antagonists. We administered the drugs 30 minutes after SE onset, when the glutamate level would have been high. A competitive AMPA receptor antagonist such as NS1209 might be displaced by high agonist concentrations (Kenakin, T., 2006), possibly explaining why NS1209 must be given as a continuous infusion and has limited effects (Pitkänen et al., 2007). Noncompetitive receptor antagonists as PER and GYKI52466 are thought to confer 'insurmountable' blockade of receptors, maintaining antagonism despite high agonist concentrations (high glutamate levels in SE). This constant blockade 
may enhance the effects in drug resistant SE. However, because GYKI52466 was tested via two intraperitoneal bolus injections given 15 minutes apart which was not meant to terminate SE immediately, it is not clear whether it could exert the same neuroprotective effect as PER (Fritsch et al., 2010).

Neuronal loss in the lithium pilocarpine model has also been reported to resemble that from ischemic injury (Lucchi et al., 2013; Curia et al., 2014). Both DZP (Schwartz et al., 1995) and PER (Niu et al., 2017) protect against neuronal loss in ischemic lesions. Because the synaptic and cellular events caused by brain ischemia are similar to those induced by epilepsy, the neuroprotective effect of PER against ischemic lesions shown in a previous study (Calabresi et al., 2003) may demonstrate the potent effects in SE from diverse aspects.

The level of neuroprotection provided by PER varied by region in the treated rats whose seizures continued. The remaining seizures in rats treated with 2 $\mathrm{mg} / \mathrm{kg}$ PER were under Racine score 2 and were accompanied by partial attenuation of neuronal loss in CA1 and Pir and full prevention of neuronal loss in MD (Fig. 3). In fact, there was no correlation between the intensities of preserved neurons in CA1 and MD (data not shown), suggesting that the neuroprotective effects of PER on MD and CA1 are independent. The regional differences in neuroprotective effects might reflect different levels of seizure suppression; that is, PER may have suppressed seizure more fully in MD than in CA1 and Pir. The seizure-induced intracellular $\mathrm{Ca}^{2+}$ concentration is much higher in MD than in dorsal CA1 and Pir in adult rats with SE (Friedman et al., 
2008). Because the degree of $\mathrm{Ca}^{2+}$ influx contributes to the level of neuronal injury (Delorenzo et al., 2005), neurons in MD may be highly susceptible to neurodegeneration. PER, however, more strongly prevented neuronal loss in MD than in CA1 and Pir. The hippocampus and Pir are essential areas for the initiation of limbic seizures (Turski et al.,1983), whereas MD receives inputs from these limbic areas and is essential for propagating seizures that originate there (Tortorella et al., 1997; Cassidy and Gale, 1998; Rogawski, 2013; Bertram et al., 2001, 2008). Thus, greater seizure suppression in MD than in the hippocampus and Pir implies that PER had more effect on seizure propagation than on the initiation of SE. This hypothesis is supported by the report of Cassidy and Gale (1998), which suggests that MD is required for the further development of seizures initiated in the limbic system, and this excitatory transmission is primarily glutamatergic. Moreover, the thalamus contains abundant AMPA receptors that are important for mediating seizure propagation (Rogawski, 2013). Taken together, all of these findings support our conclusion that PER suppressed seizures by acting on AMPA receptors, which contribute to seizure development in SE. That may explain why PER confers greater seizure control in patients with secondary generalization and primary generalized tonic-clonic seizure in clinical use (Steinhoff et al., 2013; French at al., 2015).

Neuronal loss in hippocampus and thalamus has resulted in severe postictal cognitive dysfunction and the appearance of later SRS in both SE models and patients with SE (de Oliveira et al., 2008; Cassidy and Gale, 1998; 
Helmstaedter, 2007; Sheppard and Lippé, 2012; Curia et al., 2008; Klitgaard et al., 2002; Trinka et al., 2015). Prevention of neuronal loss in these areas prevented later cognitive dysfunction and the appearance of SRS (Cunha et al., 2009; Yang et al., 2009; Brandt et al., 2015). In this study, we demonstrated that PER has a strong ability to terminate seizures and a clear neuroprotective effect in the lithium-pilocarpine rat model. However, we have not evaluated long-term behavioral changes after SE. The effect of PER on SRS development and various neurological deficits, including cognitive dysfunction, should be studied. 


\section{Conclusion}

The administration of PER to rats experiencing DZP-resistant SE significantly protected multiple key brain areas from neuronal loss by terminating the seizures. The neuroprotective effects of PER were more potent in a region associated with the generalization of limbic seizures, MD, than in CA1 or Pir, which are associated with seizure initiation. These results suggest that the suppression of seizure generalization might be a characteristic property of PER. 


\section{References:}

Barygin, O.I., 2016. Inhibition of calcium-permeable and calcium-impermeable AMPA receptors by perampanel in rat brain neurons. Neurosci Lett. 633, 146151.

Bertram, E.H., Mangan, P.S., Zhang, D.X., Scott, C.A., Williamson, J.M., 2001. The midline thalamus: alterations and a potential role in limbic epilepsy. Epilepsia. 42, 967-978.

Bertram, E.H., Zhang, D.X., Williamson, J.M., 2008. Multiple roles of midline dorsal thalamic nuclei in induction and spread of limbic seizures. Epilepsia. 49, 256-268.

Brandt, C., Töllner, K., Klee, R., Bröer, S., Löscher, W., 2015. Effective termination of status epilepticus by rational polypharmacy in the lithiumpilocarpine model in rats: Window of opportunity to prevent epilepsy and prediction of epilepsy by biomarkers. Neurobiol Dis. 75, 78-90.

Brophy, G.M., Bell, R., Claassen, J., Alldredge, B., Bleck, T.P., Glauser, T., Laroche, S.M., Riviello, J.J. Jr., Shutter, L., Sperling, M.R., Treiman, D.M., Vespa, P.M., Neurocritical Care Society Status Epilepticus Guideline Writing Committee, 2012. Guidelines for the evaluation and management of status epilepticus. Neurocrit Care. 17, 3-23. 
Calabresi, P., Cupini, L.M., Centonze, D., Pisani, F., Bernardi, G., 2003.

Antiepileptic drugs as a possible neuroprotective strategy in brain ischemia. Ann Neurol. 53, 693-702.

Cassidy, R.M., Gale, K., 1998. Mediodorsal thalamus plays a critical role in the development of limbic motor seizures. J Neurosci. 18, 9002-9009.

Chen, J.W., Naylor, D.E., Wasterlain, C.G., 2007. Advances in the pathophysiology of status epilepticus. Acta Neurol Scand Suppl. 186, 7-15.

Choi, D.W., 1988. Glutamate neurotoxicity and diseases of the nervous system. Neuron. 1, 623-634.

Clifford, D.B., Olney, J.W., Maniotis, A., Collins, R.C., Zorumski, C.F., 1987. The functional anatomy and pathology of lithium-pilocarpine and high-dose pilocarpine seizures. Neuroscience. 23, 953-968.

Cunha, A.O., Mortari, M.R., Liberato, J.L., dos Santos, W.F., 2009. Neuroprotective effects of diazepam, carbamazepine, phenytoin and ketamine after pilocarpine-induced status epilepticus. Basic Clin Pharmacol Toxicol. 104, 470-477.

Curia, G., Longo, D., Biagini, G., Jones, R.S., Avoli, M., 2008. The pilocarpine model of temporal lobe epilepsy. J Neurosci Methods. 172, 143-157.

Curia, G., Lucchi, C., Vinet, J., Gualtieri, F., Marinelli, C., Torsello, A., Costantino, L., Biagini, G., 2014. Pathophysiogenesis of mesial temporal lobe 
epilepsy: is prevention of damage antiepileptogenic? Curr Med Chem. 21, 663688.

Delorenzo, R.J., Sun, D.A., Deshpande, L.S., 2005. Cellular mechanisms underlying acquired epilepsy: the calcium hypothesis of the induction and maintainance of epilepsy. Pharmacol Ther. 105, 229-266.

de Oliveira, D.L., Fischer, A., Jorge, R.S., da Silva, M.C., Leite, M., Gonçalves, C.A., Quillfeldt, J.A., Souza, D.O., e Souza, T.M., Wofchuk, S., 2008. Effects of early-life LiCl-pilocarpine-induced status epilepticus on memory and anxiety in adult rats are associated with mossy fiber sprouting and elevated CSF S100B protein. Epilepsia. 49, 842-852.

Dubé, C., Richichi, C., Bender, R.A., Chung, G., Litt, B., Baram, T.Z., 2006. Temporal lobe epilepsy after experimental prolonged febrile seizures: prospective analysis. Brain. 129, 911-922.

Eslami, S.M., Moradi, M.M., Ghasemi, M., Dehpour, A.R., 2016. Anticonvulsive Effects of Licofelone on status epilepticus induced by lithium-pilocarpine in Wistar rats: a role for inducible Nitric Oxide Synthase. J Epilepsy Res. 6, 51-58.

French, J.A., Krauss, G.L., Wechsler, R.T., Wang, X.F., DiVentura, B., Brandt, C., Trinka, E., O'Brien, T.J., Laurenza, A., Patten, A., Bibbiani, F., 2015. Perampanel for tonic-clonic seizures in idiopathic generalized epilepsy A randomized trial. Neurology. 85, 950-957. 
Friedman, L.K., Saghyan, A., Peinado, A., Keesey, R., 2008. Age- and regiondependent patterns of $\mathrm{Ca}^{2+}$ accumulations following status epilepticus. Int. J. Dev Neurosci. 26, 779-790.

Fritsch, B., Stott, J.J., Joelle Donofrio, J., Rogawski, M.A., 2010. Treatment of early and late kainic acid-induced status epilepticus with the noncompetitive AMPA receptor antagonist GYKI 52466. Epilepsia. 51, 108-117.

Goodkin, H.P., Yeh, J.L., Kapur, J., 2005. Status epilepticus increases the intracellular accumulation of GABAA receptors. J Neurosci. 25, 5511-5520.

Goodkin, H.P., Joshi, S., Mtchedlishvili, Z., Brar, J., Kapur, J., 2008. Subunitspecific trafficking of GABA(A) receptors during status epilepticus. J Neurosci. $28,2527-2538$.

Gorter, J.A., Gonçalves Pereira, P.M., van Vliet, E.A., Aronica, E., Lopes da Silva, F.H., Lucassen, P.J., 2003. Neuronal cell death in a rat model for mesial temporal lobe epilepsy is induced by the initial status epilepticus and not by later repeated spontaneous seizures. Epilepsia. 44, 647-658.

Grooms, S.Y., Opitz, T., Bennett, M.V., Zukin, R.S., 2000. Status epilepticus decreases glutamate receptor 2 mRNA and protein expression in hippocampal pyramidal cells before neuronal death. Proc Natl Acad Sci U S A. 97, 36313636. 
Hanada,T., Ido, K., Kosasa, T., 2014. Effect of perampanel, a novel AMPA antagonist, on benzodiazepine-resistant status epilepticus in a lithiumpilocarpine rat model. Pharmacol Res Perspect. 2, e00063.

Heinemann, U., Buchheim, K., Gabriel, S., Kann, O., Kovács, R., Schuchmann, S., 2002a. Cell death and metabolic activity during epileptiform discharges and status epilepticus in the hippocampus. Prog Brain Res. 135, 197-210.

Heinemann, U., Buchheim, K., Gabriel, S., Kann, O., Kovács, R., Schuchmann, S., 2002b. Coupling of electrical and metabolic activity during epileptiform discharges. Epilepsia. 43 Suppl 5, 168-173.

Helmstaedter, C., 2007. Cognitive outcome of status epilepticus in adults. Epilepsia. 48 Suppl 8, 85-90.

Holtkamp, M., Othman, J., Buchheim, K., Meierkord, H., 2005. Predictors and prognosis of refractory status epilepticus treated in a neurological intensive care unit. J Neurol Neurosurg Psychiatry. 76, 534-539.

Imran, I., Hillert, M.H., Klein, J., 2015. Early metabolic responses to lithium/pilocarpine-induced status epilepticus in rat brain. J Neurochem. 135, $1007-1018$.

Kenakin, T., 2006. A pharmacology primer. 2nd Edition. Theory, applications, and methods. Academic Press 
Klitgaard, H., Matagne, A., Vanneste-Goemaere, J., Margineanu, D.G., 2002. Pilocarpine-induced epileptogenesis in the rat: impact of initial duration of status epilepticus on electrophysiological and neuropathological alterations. Epilepsy Res. 51, 93-107.

Liu, M., Liang, Y., Chigurupati, S., Lathia, J.D., Pletnikov, M., Sun, Z., Crow, M., Ross, C.A., Mattson, M.P., Rabb, H., 2008. Acute kidney injury leads to inflammation and functional changes in the brain. J Am Soc Nephrol. 19, 13601370.

Löscher, W., Brandt, C., 2010. Prevention or modification of epileptogenesis after brain insults: experimental approaches and translational research. Pharmacol Rev. 62, 668-700.

Lowenstein, D.H., Alldredge, B.K., 1998. Status epilepticus. N Engl J Med. 338, 970-976.

Lucchi, C., Curia, G., Vinet, J., Gualtieri, F., Bresciani, E., Locatelli, V., Torsello, A., Biagini, G., 2013. Protective but not anticonvulsant effects of ghrelin and JMV-1843 in the pilocarpine model of Status epilepticus. PLoS One. 28;8, e72716.

Mayer, S.A., Claassen, J., Lokin, J., Mendelsohn, F., Dennis, L.J., Fitzsimmons, B.F., 2002. Refractory status epilepticus: frequency, risk factors, and impact on outcome. Arch Neurol. 59, 205-210. 
Meierkord, H., Boon, P., Engelsen, B., Göcke, K., Shorvon, S., Tinuper, P., Holtkamp, M., 2006. EFNS guideline on the management of status epilepticus. Eur J Neurol. 13, 445-450.

Meierkord, H., Boon, P., Engelsen, B., Göcke, K., Shorvon, S., Tinuper, P., Holtkamp, M., European Federation of Neurological Societies., 2010. EFNS guideline on the management of status epilepticus in adults. Eur J Neurol. 17, 348-355.

Naylor, D.E., Liu, H., Wasterlain, C.G., 2005. Trafficking of GABA(A) receptors, loss of inhibition, and a mechanism for pharmacoresistance in status epilepticus. J Neurosci. 25, 7724-7733.

Niu, H.X., Wang, J.Z., Wang, D.L., Miao, J.J., Li, H., Liu, Z.G., Yuan, X., Liu, W., Zhou, J.R., 2017. The Orally Active Noncompetitive AMPAR Antagonist Perampanel Attenuates Focal Cerebral Ischemia Injury in Rats. Cell Mol Neurobiol. 2017 Apr 11.

Pellegrini-Giampietro, D.E., Gorter, J.A., Bennett, M.V., Zukin, R.S., 1997. The GluR2 (GluR-B) hypothesis: $\mathrm{Ca}^{2+}$-permeable AMPA receptors in neurological disorders. Trends Neurosci. 20, 464-470.

Pitkänen, A., Mathiesen, C., Rønn, L.C., Møller, A., Nissinen, J., 2007. Effect of novel AMPA antagonist, NS1209, on status epilepticus. An experimental study in rat. Epilepsy Res. 74, 45-54. 
Racine, R.J., 1972. Modification of seizure activity by electrical stimulation. II. Motor seizure. Electroencephalogr Clin Neurophysiol. 32, 281-294.

Rajasekaran, K., Todorovic, M., Kapur, J., 2012. Calcium-permeable AMPA receptors are expressed in a rodent model of status epilepticus. Ann Neurol. 72, $91-102$.

Rogawski, M.A., Donevan, S.D., 1999. AMPA receptors in epilepsy and as targets for antiepileptic drugs. Adv Neurol. 79, 947-963.

Rogawski, M.A., 2013. AMPA receptors as a molecular target in epilepsy therapy. Acta Neurol Scand Suppl. (197), 9-18.

Rossetti, A.O., Lowenstein, D.H., 2011. Management of refractory status epilepticus in adults: still more questions than answers. Lancet Neurol. 10, 922930.

Schwartz, R.D., Yu, X., Katzman, M.R., Hayden-Hixson, D.M., Perry, J.M., 1995. Diazepam, given postischemia, protects selectively vulnerable neurons in the rat hippocampus and striatum. J Neurosci. 15, 529-539.

Sheppard, E., Lippé, S., 2012. Cognitive outcome of status epilepticus in children. Epilepsy Res Treat. 2012, 984124.

Steinhoff, B.J., Ben-Menachem, E., Ryvlin, P., Shorvon, S., Kramer, L., Satlin, A., Squillacote, D., Yang, H., Zhu, J., Laurenza, A., 2013. Efficacy and safety of 
adjunctive perampanel for the treatment of refractory partial seizures: a pooled analysis of three phase III studies. Epilepsia. 54, 1481-1489.

Suchomelova, L., Baldwin, R.A., Kubova, H., Thompson, K.W., Sankar, R., Wasterlain, C.G., 2006. Treatment of experimental status epilepticus in immature rats: dissociation between anticonvulsant and antiepileptogenic effects. Pediatr Res. 59, 237-243.

Tortorella, A., Halonen, T., Sahibzada, N., Gale, K., 1997. A crucial role of the alpha-amino-3-hydroxy-5-methylisoxazole-4-propionic acid subtype of glutamate receptors in piriform and perirhinal cortex for the initiation and propagation of limbic motor seizures. J Pharmacol Exp Ther. 280, 1401-1405.

Trinka, E., Cock, H., Hesdorffer, D., Rossetti, A.O., Scheffer, I.E., Shinnar, S., Shorvon, S., Lowenstein, D.H., 2015. A definition and classification of status epilepticus--Report of the ILAE Task Force on Classification of Status Epilepticus. Epilepsia. 56,1515-1523.

Turski, W.A., Cavalheiro, E.A., Schwarz, M., Czuczwar, S.J., Kleinrok, Z., Turski, L., 1983. Limbic seizures produced by pilocarpine in rats: behavioural, electroencephalographic and neuropathological study. Behav Brain Res. 9, 315335.

Turski, L., Ikonomidou, C., Turski, W.A., Bortolotto, Z.A., Cavalheiro, E.A., 1989. Review: cholinergic mechanisms and epileptogenesis. The seizures 
induced by pilocarpine: a novel experimental model of intractable epilepsy. Synapse. 3, 154-171.

Wasterlain, C.G., Fujikawa, D.G., Penix, L., Sankar, R., 1993.

Pathophysiological mechanisms of brain damage from status epilepticus. Epilepsia. 34 Suppl 1, S37-53.

Yang, J., Xu, J.T., Huang, Y.G., Song, Y.B., Zhen, J., Ma, X.J., Xu, J.C., Xue, H., Zhang, X.X., Xing, X.X., 2009. Erythropoietin pre-treatment prevents cognitive impairments following status epilepticus in rats. Brain Res. 1282, 5766. 


\section{Figures:}

Figure. 1

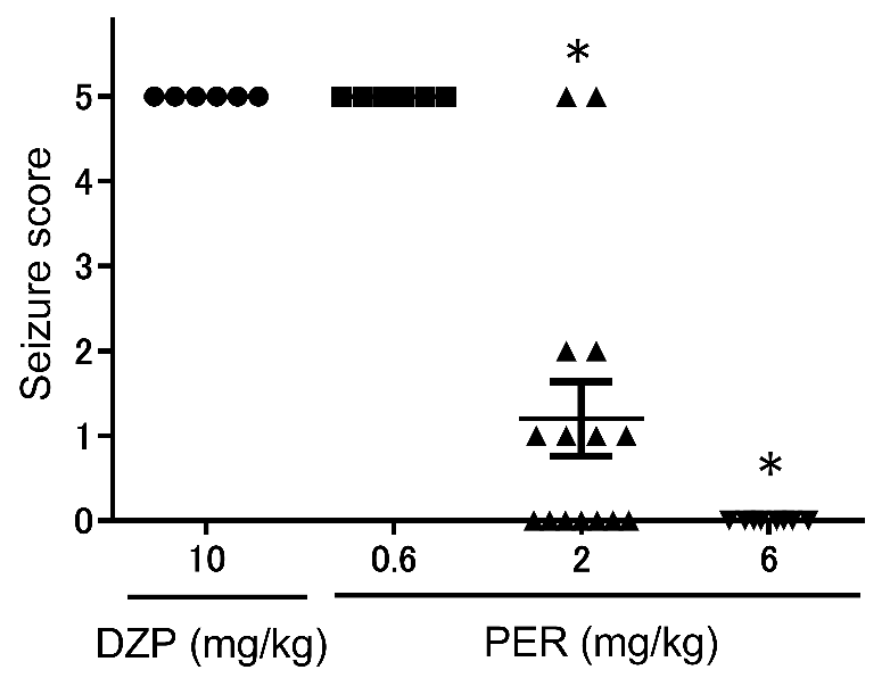

Fig. 1. Effects of perampanel (PER) and diazepam (DZP) on lithium-pilocarpineinduced seizures. DZP, $\mathrm{n}=6$; PER $0.6 \mathrm{mg} / \mathrm{kg}, \mathrm{n}=6$; PER $2 \mathrm{mg} / \mathrm{kg}, \mathrm{n}=15$; PER $6 \mathrm{mg} / \mathrm{kg}, \mathrm{n}=8 .{ }^{*} p<0.05$, versus the DZP-treated group. 
Figure. 2

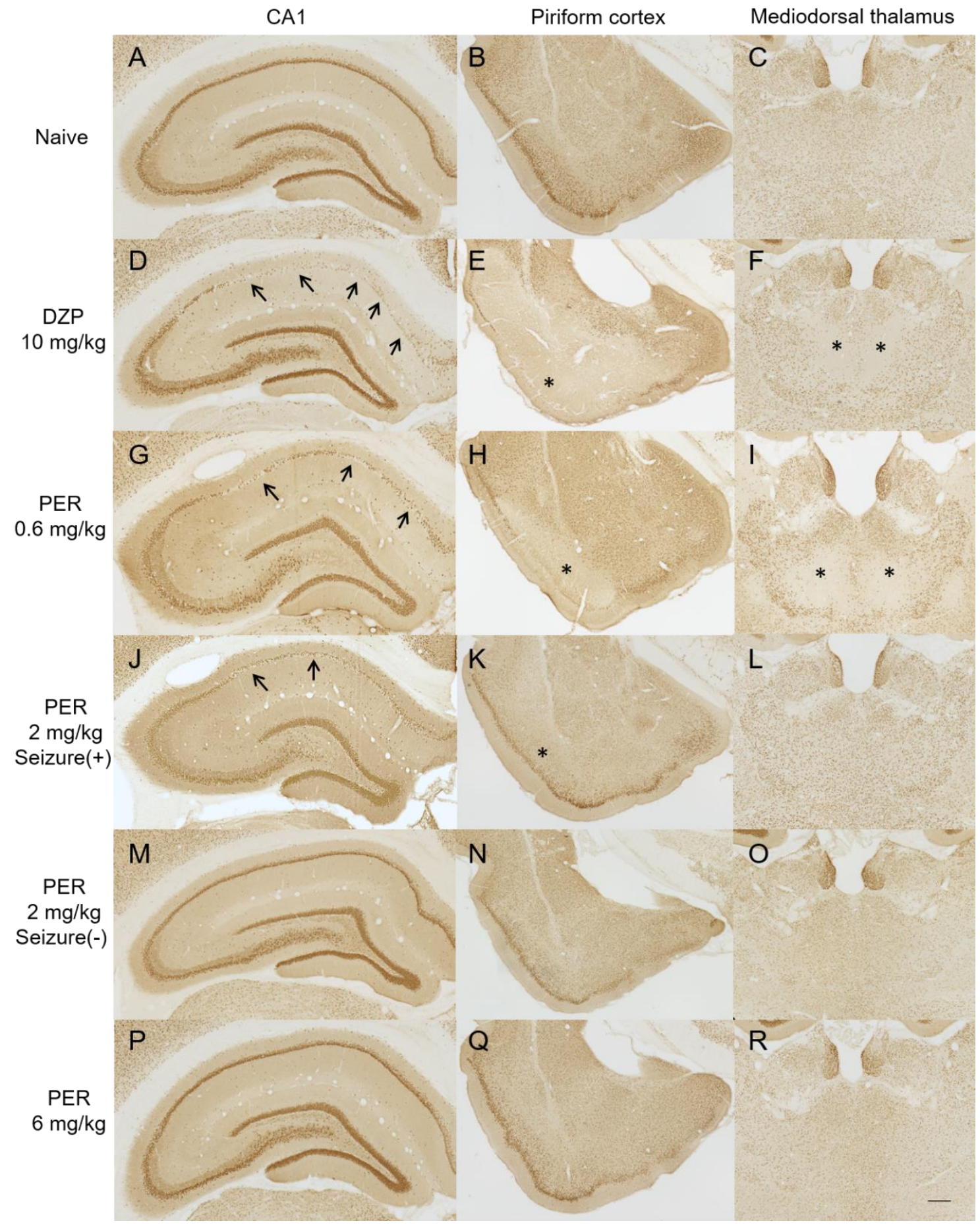


Fig. 2. Photomicrographic images of CA1 (left), piriform cortex (middle), and mediodorsal thalamus (right) in diazepam (DZP)- or perampanel (PER)-treated rats. The staining was defined as weakly positive, positive, or strongly positive on the basis of the color intensity, and the pixels in the positive and strongly positive categories were counted. Seizure (+), seizures continued after treatment; seizure (-), seizures terminated after treatment. Scale bar, $300 \mu \mathrm{m}$. Asterisks show the area of neuronal loss in piriform cortex and mediodorsal thalamus. Arrows indicate the area of neuronal loss in CA1. 
Figure. 3
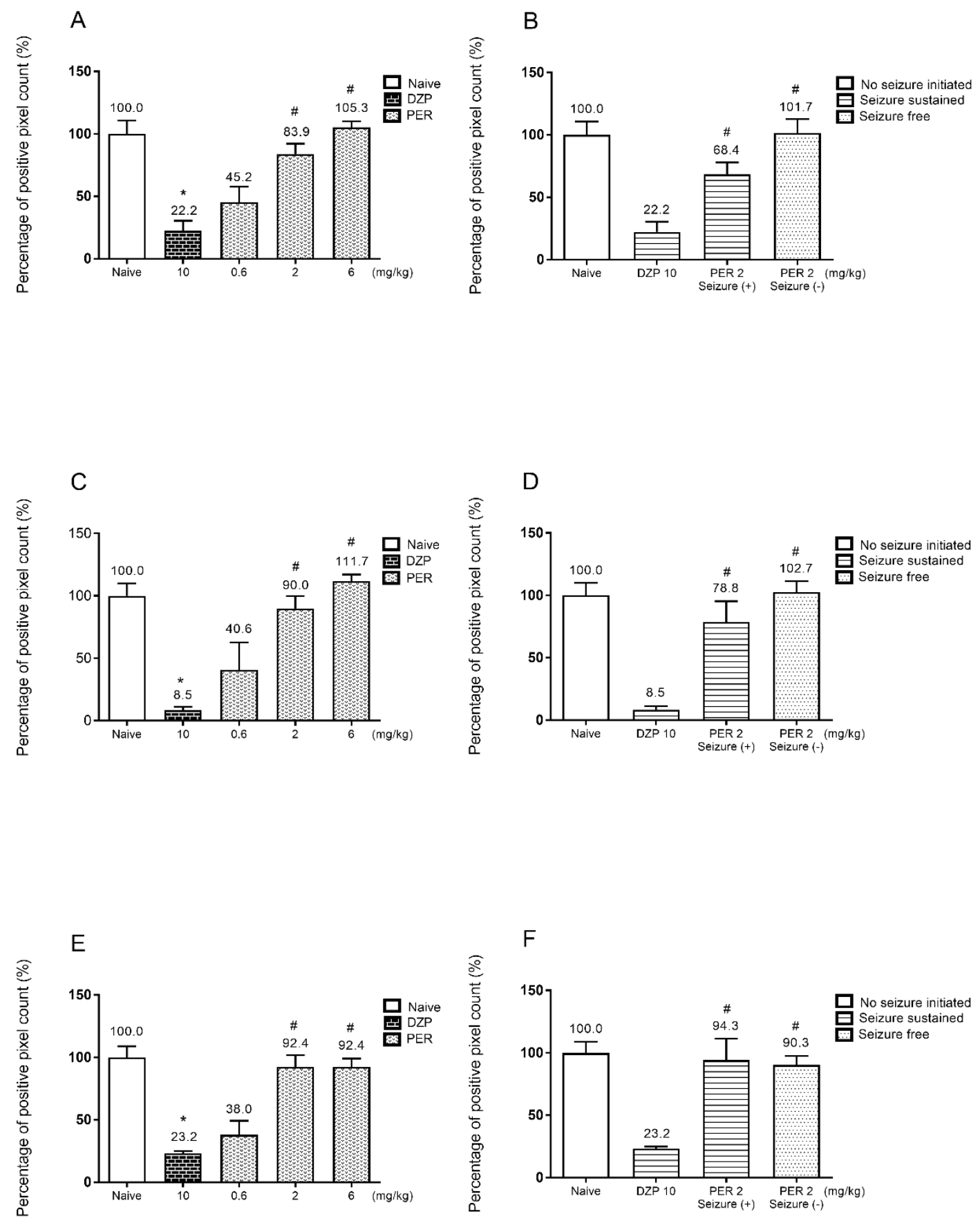
Fig. 3. Effects of diazepam (DZP) and perampanel (PER) on neuronal survival one week after SE initiation. Data are shown relative to the pixel counts for the naive group, which were set at $100 \%$. The error bars represent the standard error of the mean. (A) and (B) are from the CA1 subregion of the hippocampus, average pixel counts of naïve group was 146,$013 ;(C)$ and (D) are from the piriform cortex, average pixel counts of naïve group was 479,352; $(E)$ and $(F)$ are from the mediodorsal thalamic nucleus, average pixel counts of naïve group was $430,930 . \mathrm{n}=6-15 .{ }^{*} p<0.05$ versus the naive group. $\# p<0.05$ versus the DZP-treated group. (B), (E), and (F) showed the level of neuronal survival in the subgroups of $2 \mathrm{mg} / \mathrm{kg}$ of PER which are seizure sustained group [seizure (+), $\mathrm{n}$ $=8]$ ) and seizure free group [seizure $(-), n=7$ ]. 
Figure. 4
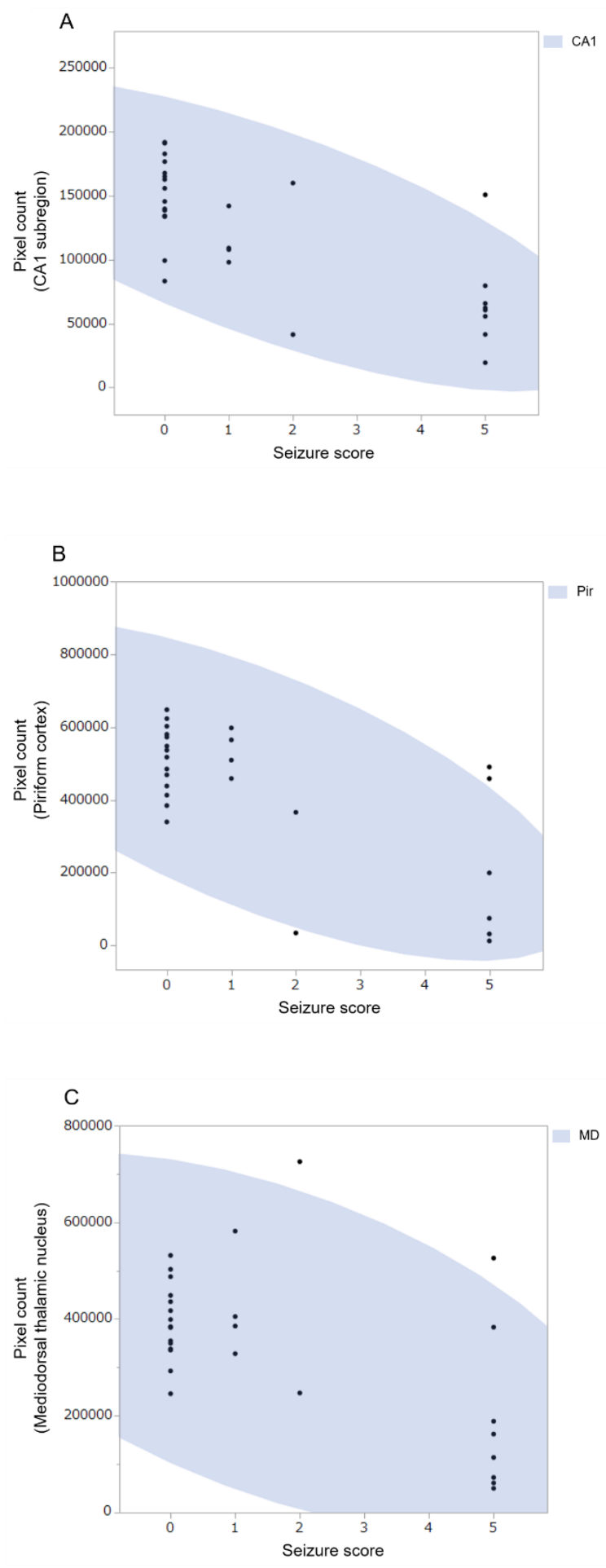
Fig. 4. The correlation of seizure score and the neuroprotective effect of perampanel (PER). The Pearson's $r$ value was -0.72 in the CA1 subregion (A, $p$ $<0.05),-0.68$ in the piriform cortex $(\mathrm{B}, p<0.05)$, and -0.52 in the mediodorsal thalamic nucleus $(C, p<0.05)$. 


\section{Supplementary file:}

Supplementary table. 1

Latency to lithium-pilocarpine induced SE initiation

\begin{tabular}{rccccc}
\hline & DZP & & \multicolumn{3}{c}{ PER } \\
\cline { 2 - 4 } \cline { 5 - 6 }$(\mathrm{mg} / \mathrm{kg})$ & 10 & & 0.6 & 2 & 6 \\
\hline $\begin{array}{r}\text { Latency to SE } \\
\text { initiation (min) }\end{array}$ & $38.9 \pm 3.50$ & & $35.3 \pm 4.56$ & $36.3 \pm 2.74$ & $41.8 \pm 3.92$ \\
\hline
\end{tabular}

Latency to lithium-pilocarpine induced SE initiation were not different among the various treatment groups ( $P>0.05$; one-way ANOVA). 